Original Research Paper

\title{
Degradation of Power Generation Performance due to Effects of Various Ice Shapes and Accretions on Wind Turbine Blades
}

\author{
${ }^{1}$ Aditya Bagade, ${ }^{1}$ Changki Mo and ${ }^{2}$ Abdelhamid Mazher \\ ${ }^{I}$ School of Mechanical and Materials Engineering, Washington State University Tri-Cities, Richland, USA \\ ${ }^{2}$ Department of Nuclear Engineering, King Abdulaziz University, KSA
}

\section{Article history}

Received: 01-01-2015

Revised: 03-05-2015

Accepted: 29-07-2015

Corresponding Author: Aditya Bagade

School of Mechanical and Materials Engineering, Washington State University Tri-Cities, Richland, USA E-mail: aditbagade@gmail.com

\begin{abstract}
In today's world, green energy has become a key initiative as an alternative energy resource. Wind turbines are widely used to harvest wind energy in seasonal and cold environments. Although efficient, cold weather conditions negatively affects wind turbine operations due to ice formation. Damage from icing is seen on blade-tips when super-cooled water droplets that form in colder environments rapidly freeze and accumulate. Different forms of ice structures are formed along the leading edge to the trailing edge of the turbine blade and are classified into horn, rime and glaze ice. These various ice structures can cause power losses, mechanical and electrical failures and pose serious safety hazards (e.g., ice throwing). Ongoing efforts have been in place to develop anti-icing and de-icing strategies, but only a few are available on the market. In this computational study using ANSYS 14, a variable pitched National Renewable Energy Laboratory (NREL) and National Advisory Committee for Aeronautics (NACA) airfoils are used to determine the effects of various ice formations along the cord of turbine blade. Ice accretions on turbine blade can cause significant performance issues such as decreased lift and increased drag leading to performance and energy losses. Understanding the flow behavior of iced airfoil is critical in determining what geometric features of ice contributes to the performance degradation and aerodynamic failures in wind turbines. This study may help optimize future designs and implementation of ice mitigations systems to maximize turbine power output.
\end{abstract}

Keywords: Wind Turbine, Ice Accretions, Aerodynamic Performance, Computational Fluid Dynamics, Numerical Simulation

\section{Introduction}

Wind turbines have recently gained popularity as a alternative source for green energy. Wind turbines transform kinetic energy of the ambient wind into mechanical energy, which is used by the turbine to produce electricity. Wind turbines come in various configurations. Horizontal and vertical axis wind turbines are the two kinds which are widley used in commercial application. The vertical wind turbines are tailored with helical shaped blades and are driven by wind approaching from all directions. Because of this flexibility, vertical axis wind turbines are ideal for applications where wind is not sustained. Horizontal axis wind turbine leads the wind industry and are commonly used in commercial wind farms. However, in residential and small applications, vertical axis turbines are common. The benefit of horizontal wind turbine is that it is able to efficiently produce more energy from a given amount of wind. Because of this flexibility and for sustained applications, horizontal axis turbines are preferred over vertical axis turbines (Corbus and Meadors, 2005; Ahmed et al., 2010; Chantharasenawong and Tipkaew, 2010). In the wind driven turbines, the pitched blades on the turbine act like a lift device, as opposed to a drag device. Drag devices depend on the wind to push and are relatively inefficient. In comparison, lift devices instead use airfoils. The airfoils are shaped to create lift as wind flows past (Sicot et al., 2008). A component of the generated lift creates a torque on the blade which causes the rotor of the wind turbine to rotate around its axis. 
This evolving technology and its performance in cold weather conditions are the underlying focus of this study. More specifically, this study is intended at gaining clear understanding of the flow fields around the turbine blade and its effects on power productivity.

Atmospheric icing of structures has been classified as the frequently encountered problem in the energy sector. Although it is a major problem to the wind power industry as it has expanded into more cold weather regions where the wind resource is extraordinary.

The fast growing commercial establishments of wind farms in the cold climates demand additional knowledge on how wind turbines perform in extremely low temperatures and icing conditions. Although wind is plentiful in cold climate, icing has been key to energy losses. Wind turbine manufacturers have already developed cold climate mitigation packages and there are only a few different de-icing and anti-icing solutions available on the market, but the icing of blades still requires significant work (Parent and Ilinca, 2011). There are several ice detection systems commercially available, but have proven inadequate. However, continous efforts are in process to improve the ice detection and mitigation sytems.

Ice accretion on wind turbine blades can be a hazard from ice throwing, mechanical failure and resulting in increased wear of the components. The effects of ice formation on the turbine blades can lead to aerodynamic failures and result in significant power production losses. It is also shown experimentally and by numerical simulations that icing on turbine blades leads to aerodynamic deficiency and is directly proportional to the turbine inefficiency.

Presently, there are two areas of icing studies. The first one is focuses on icing effects, which studies the flow field characteristics around the airfoil and second is the formation of ice structures on the airfoil from ice accretion, which mainly focuses on the advances of ice profiles. Glaze and horn ice profiles are the most commonly discussed (Cao, 2008). The steps involved in modeling the icing problem includes the selection of airfoil, creation of the geometry and refinement of mesh using Computational Fluid Dynamics (CFD) software.

The source for ice accretion is due to super cooled water droplets impacting the leading surface of the airfoil. This ice accumulation can significantly alter the the aerodynamic shape of airfoils and likewise significantly reduce its aerodynamic performance. Hence understanding the mechanisms and effects of ice accretion is of great importance to energy harvesting in colder climates (Cao et al., 2008). Different climatic condtions contribute to various forms of ice accretions. Depending on the icing mechanism, ice accretions can be categorized as glaze and horn profiles.
Glaze ice is commonly observed in low freezing temperatures. This phenomen occurs when super cooled droplets freeze instantly as they impact onto the airfoil surface. In comparision, horn ice occurs at a relatively higher temperatures, under which the droplets freeze partially as they impinge and then freeze gradually during the flow along the airfoil.

\section{Methods}

\section{Optimal Power Output and Wind Speed}

Wind farms are progressively being built in colder climates, where they are intermittently exposed to atmospheric icing. Many cold regions have wide open spaces and excellent wind resources. However, climatic accumulation of icing is know to cause turbine failure from increased fatigue loads (Ganander and Ronsten, 1998) and likewise reduce performance resulting in power losses (Jasinski et al., 1998). Betz equation, is an ideal model developed to estimate total power output from an ideal turbine. Betz limit defines turbine coefficient of performance, $C_{P i}$ as:

$C_{P_{i}}=\frac{P}{P_{\text {Wind }}}=\frac{\int_{v_{h}}^{R} \Omega d T}{\frac{1}{2} \rho \pi R^{2} V^{3}}$

Where:

$P \quad=$ The actual power captured by the rotor

$P_{\text {wind }}=$ The theoretical power available in the idealized air flow

The equation for coefficient of power was modified to integrate drag and lift coefficients as derived by Ingram (2011):

$$
C_{P i}=\frac{8}{\lambda^{2}} \int_{\lambda_{h}}^{\lambda} Q \lambda_{r}^{3} a^{\prime}(1-a)\left[1-\frac{C_{D}}{C_{L}} \tan \beta\right] d \lambda_{r}
$$

Where:

$$
a^{\prime}=\frac{\omega}{2 \Omega}, a=\frac{V_{1}-V_{2}}{V_{1}} \text {, and } \lambda_{r}=\frac{\Omega_{r}}{V}
$$

An ideal wind turbine operates at constant wind speed and experimental data (Johnson, 1985) suggests that the optimal power output is achieved at $14 \mathrm{~m} / \mathrm{s}$. At greater wind speeds, the turbine is designed to limit its maximum output with no further increase in power production as depicted in Fig. 1. Based on this report, wind speeds between of $13 \mathrm{~m} / \mathrm{s}$ to $15 \mathrm{~m} / \mathrm{s}$ was examined. 


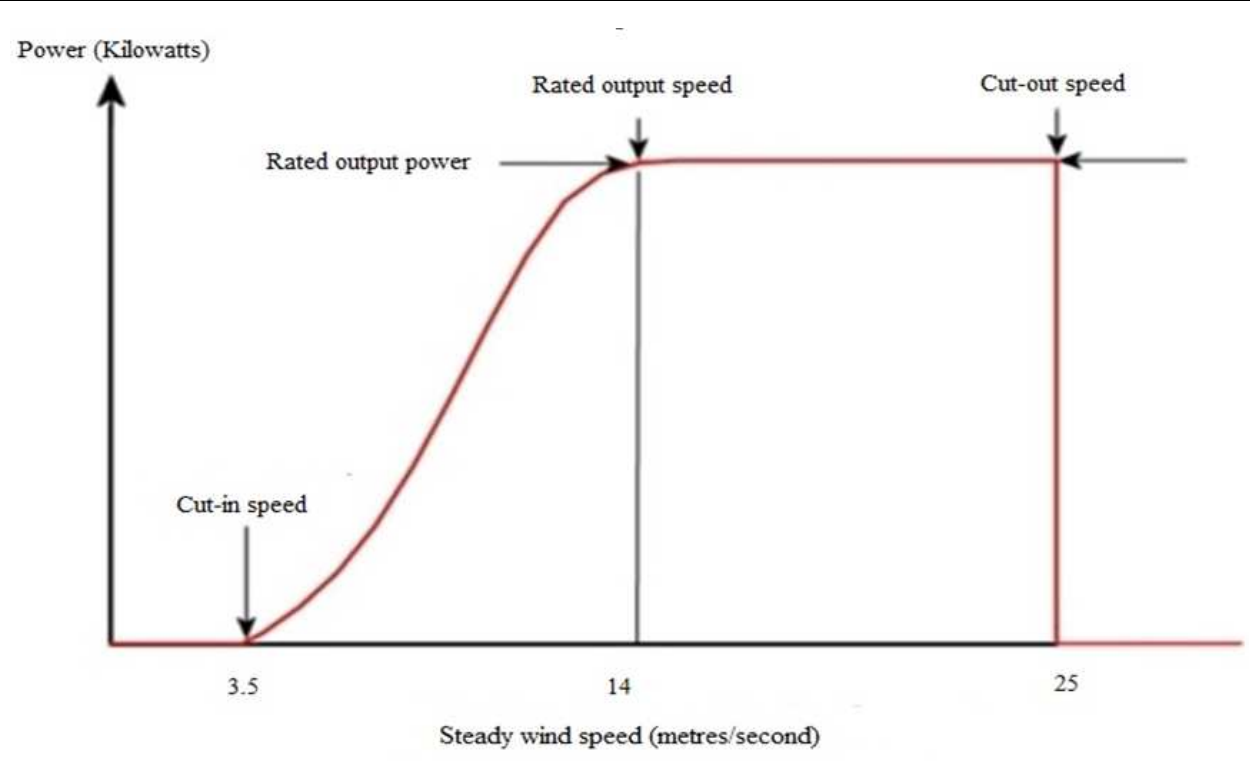

Fig. 1. Power Output Curve: Wind Turbine (WTPC, 1999)

\section{Mathematical Formulation and Turbulence Model}

The CFD solver is set to solve equations for flow conservation and transport equations comprehensive of mass and momentun as the flow behaviour changes turbulent. The equation for conservation of mass can be written as follows:

$\frac{\partial \rho}{\partial t}+\nabla \cdot(\rho \vec{u})=S_{m}$

Mass conservation equation shown in Equation 3 is valid for compressible and incompressible flows. Equation 4 refrences conservation of momentum

$\frac{\partial}{\partial t}(\rho \vec{u})+\nabla \cdot(\rho \vec{u} \vec{u})=-\nabla p+\nabla \cdot(\tilde{\tau})+\rho \vec{g}+\vec{F}$

For two dimensional flow the continuity equation is:

$\frac{\partial}{\partial x}+\frac{\partial v}{\partial x}=0$

Momentum equations for two dimensional viscous flow are:

$\rho \frac{D u}{D t}=-\frac{\partial p}{\partial x}+\frac{\partial \tau_{x x}}{\partial x}+\frac{\partial y x}{\partial y}+\rho f_{x}$

$\rho \frac{D u}{D t}=-\frac{\partial p}{\partial y}+\frac{\partial \tau_{x y}}{\partial x}+\frac{\partial y y}{\partial y}+\rho f_{y}$

Spalart-Allmaras coefficients are obtained by solving Equations 6-7 respectively (Ahmed et al., 2013).

\section{Spalart-Allmaras Turbulence Method}

The Spalart and Allmaras method was specially developed for aerospace applications and included a simplified equation to solve transport equation for turbulent viscosity. The Spalart-Allmaras method has been verified to be more accurate in solving wall bounded flows subjected to adverse pressure gradients than ReNormalization Group (RNG) k- $\varepsilon$, Standard k- $\varepsilon$ and realizable $\mathrm{k}-\varepsilon$ methods. Using the Spalart-Allmaras method, it was also observed that the near wall gradients of the transported variables in the Spalart-Allmaras model were much smaller than the the k- $\varepsilon$ and $k-\omega$ models (Liu and Wang, 2011). Therefore Spalart-Allmaras method is chosen for this CFD application.

\section{Selection of Airfoil}

For modeling flow characetistics of $2 \mathrm{D}$ airfoils, two airfoils NACA0012 and NACA4415 were selected with a 1-m standard cord length. Coordinates for the airfoils were obtained from the airfoil plotter at University of Illinois at Urbana-Champaign (UIUC, 2011) and airfoil database of National Renewable Energy Laboratory respectively (DIANE, 2005).

\section{Computational Methods}

The NACA0012, a frequently studied airfoil from the 4-digit series of NACA airfoils and the wind turbine utilized NACA4415 are considered for this study. The NACA0012 is a symmetrical airfoil whereas NACA4415 is a non-symmetrical airfoil. Velocity for the simulations were sampled between 13 and $15 \mathrm{~m} / \mathrm{s}$ and compared with the experimental data obtained from Abbott and Von Doenhoff (Hudecz et al., 2013), with no ice to validate the simulation. 
The free stream is assumed as incompressible at temperature of $-5^{\circ} \mathrm{C}$ and density of $\rho=1.32 \mathrm{~kg} / \mathrm{m}^{3}$ is used. Implicit solver was utilized along with pressure model. Calculations were performed for Angles Of Attack (AOA) ranging from $-5^{\circ}$ to $20^{\circ}$ with $5^{\circ}$ increments. ANSYS 14 was used to simulate airfoil profile, boundary conditions and meshes. Here quadrilateral meshes are used and further simplified. Ambient atmospheric condition was imposed at outlet. No slip boundary conditions are imposed for the wall. The airfoil surface is treated as wall boundary. The flow was solved using the second order upwind solution methods. Ice structures such as glaze ice and horn ice were generated using JAVAFOIL for further analysis of iced profiles.

\section{Grid Independence}

Y-plus value is an dimensionless number used to validate turbulence models. Y-plus is the dimesioneless distance between the wall to the center of the element. Turbulent flows are considerably affected by the presence of walls. In CFD, the y-plus values are frequently used to determine the mesh sizing, it is also a ratio between the laminar and turbulent flow effecting a cell. When flow is observed very close to the wall, velocity dampening is observed. However, exterior of the near-wall region, large gradients in velocity is observed. Villalpando demonstrated that flow in the near wall region was successfully observed using Spalart-Allmaras method (Villalpando et al., 2012). Spalart-Allmaras method and its fine mesh dependency on the boundary layer was also demonstrated (Salim and Cheah, 2009). Table 1 shows the values obtained from validation of for the NACA0012 at $6^{\circ}$ (AOA) using different mesh sizing. From Table 1, 15000 elements was found suitable for the analysis. This same arrangement was used to set mesh sizing for all simulations.

\section{Verification and Analysis of Aerodynamic Parameters}

In this simulation, the flow field over the NACA0012 was analyzed using Spalart-Allmaras model of equations by FLUENT solver. The comparitive solution obtained for the solver and existing experimental data from Abbott et al. (Hudecz et al., 2013) were analyzed to validate the computational results for NACA0012. Aerodynamic parameters such as the coefficient of pressure, lift coefficient, drag coefficient, flow streams, velocity and pressure contours were obtained using the Spalart-Allmaras turbulence model. For secondary verification, a special case was evaluated at $6.0 \mathrm{~m} / \mathrm{s}$ and compared with experimental results obtained from Gregory and O'Reilly (1970) as in Table 1. The same verified conditions were applied to compare aerodynamic performance between NACA 0012 and NACA 4415.

\section{Modeling Iced Airfoil Profiles}

The two major types of ice accretion analyzed in this study are glaze and horn ice profiles. Glaze ice, occurs when super cooled droplets of moisture freeze immediately after impinge onto the airfoil surface. Whereas horn ice accretions occurs when the water droplets freeze partially as they impinge and then freeze gradually flowing across the airfoil. At slightly warmer temperatures the ice melts and flows along the airfoil surface forming ridges. Horn icie generally occurs at warmer temperatures then glaze ice.

In this numerical simulation, glaze ice and horn ice forms were modeled using JAVAFOIL application (JAVA, 2007). Both ice forms have smooth surface texture, hence friction effects were not considered in this analysis. Shapes for glaze ice and horn ice were mapped by approximation and accretions studies (Shields, 2011) as shown in Fig. 2. Ice shapes in accretion studies are based on an estimation of the ambient condition provided by the time lapse management software, LEWICE and TURBICE developed by NASA (Hudecz et al., 2013). Using JAVAFOIL, the ice co-ordinates along the leading edge were mapped to coordinates $\mathrm{x} / \mathrm{c}$ and $\mathrm{y} / \mathrm{c}$ structure obtained from NASA (Tsao and Lee, 2011) and ice accretion studies by Shields (2011).

\section{Grid Generation}

In order to simulate lift and drag for the proposed airfoil, the mesh near the airfoil must be dense enough and large enough to satisfy the farfield boundary conditions. The density of the mesh generated, will also collectively map the ice forms. The initial step in performing the simulation was be to determine the mesh sizing. Mesh sizing is the key component for an accurate numerical solution. Definitive mesh sizing can be achieved by using assortment of nodes. Meanwhile using more nodes also requires a faster processing unit and additional time required to complete an interation.

Table 1. Grid independence criteria

\begin{tabular}{llll}
\hline Sample & Mesh elements & $\mathrm{C}_{\mathrm{L}}$ & Wall distance \\
\hline 1 & 15000 & 1.06 & 2.410 \\
2 & 30000 & 0.99 & 6.820 \\
3 & 45000 & 0.91 & 10.23 \\
\hline
\end{tabular}


The mesh sizing and refinement is sufficient when addition of more nodes yields no changes to the results. This study included a C-type grid topology with 15000 quadrilateral cells which proved sufficient to achieve a grid independent numerical solution. The domain height for the C-type grid topology was set to maximum of 20 chord lengths with a height of the first cell adjacent to the surface with a maximum yplus of approximately 2 (see Table 1 ).

First edges near rounded corners are densely meshed then the half circle area to control edge features, followed by the meshing the two halves of the rectangles. Structured mesh is defined by ANSYS 14. The grid generation is comprised by developing C-Mesh block structure grid with multi-block grid method. In this approach, the airfoil is placed at the center of a semi-circle, followed with a rectangular block as shown in Fig. 3. The rectangular block and the semi-circle are further divided. Quadrants are created between the four blocks to create projections. These projections define the structure relating the surface and the edges. Edge sizing on each quadrant is made to define mesh origination.

\section{Calculation using Fluent}

Airfoil is identified and treated as a wall boundary. The flow medium flowing over the airfoil is assumed to be ideal gas. It was found by (Zhou and $\mathrm{Hu}, 2006$ ) and (Lee and Bragg, 2003) that in the simulation using Spalart-Allmaras model for the of flow field around an airfoil, is more accurate than Standard k- $\varepsilon$ and realizable k- $\varepsilon$ models. For this reason, the SpalartAllmaras model with a pressure coupled method was preferred for this analysis.

Inlet velocity between 13 to $15 \mathrm{~m} / \mathrm{s}$ for a range of AOA between $\alpha=-5^{\circ}$ to $\alpha=20^{\circ}$ with increments of $\alpha$ $=5^{\circ}$ were set. These simulations were repeated for all icing shapes at various parameters, i.e. coefficient of drag, coefficients of lift and pressure coefficients. All coefficients are compared against no ice, glaze ice and horn ice profiles.

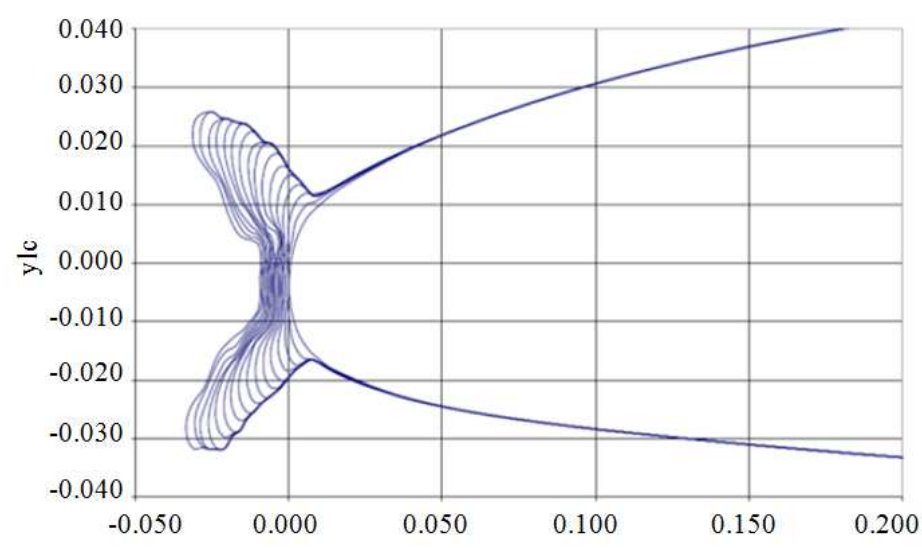

Fig. 2. Ice accretion horn ice [Tsao and Lee, 2011]

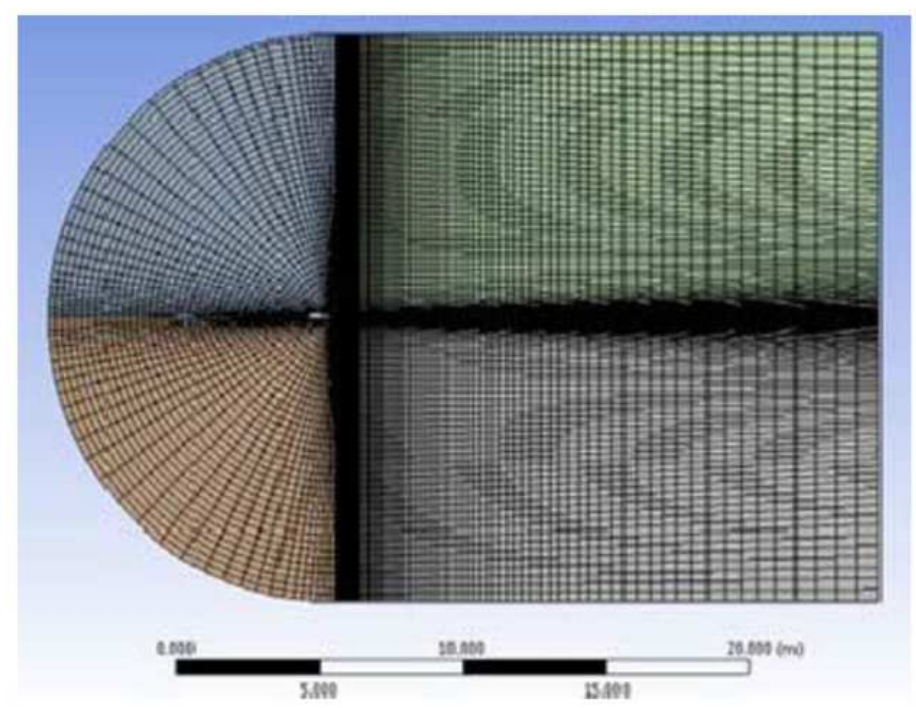

Fig. 3. C-mesh around NACA 0012 


\section{Results}

The results for NACA0012 and NACA4415 from the simulations using the Spalart-Allmaras turbulence model included plots for clean, glaze and horn ice profiles. For articular purposes only selective plots for coeffiecient of drag, coeffiecient of lift, velocity and pressure contours and streamlines are shown (Fig. 4-12). The fully development flow around the ice profiles were analyzed and importance was given to understand the flow characterstics around the airfoil. From the contour for velocity and pressure coefficients, a region of high pressure at the leading edge, also known as the stagnation point and a region of low pressure on the suctions side of the airfoil were analyzed.

\section{Discussion}

According to Bernoulli equation, when flows exhibits high velocity a low pressure gradient is anticipated. Comparison of pressure contours for clean airfoils for NACA0012 for all three velocities did not reveal any significant changes. However, ice shapes contributed significantly to the aerodynamic efficiency when compared to Abbott's wing theory (Villalpando et al., 2012). The pressure contours from AOA $\alpha=-5^{\circ}$ to $\alpha=20^{\circ}$ predicted pressure distributions showing regions of pressure gradients that were concentrated near the stagnation area close to the leading edge of the airfoil. It is observed that the pressure contours exhibited a high-pressure region adjacent to the lower surface of the airfoil. Furthermore with increasing AOA the value of pressure drop over suction side and a rise on the pressure side. From (Fig. $10-12$ ), it is evident that the flow from $\alpha=-5^{\circ}$ to $5^{\circ}$ is smooth and closely attached to the airfoil. At $\alpha=10^{\circ}$ a separation bubble starts to form at the trailing edge and at $\alpha=15^{\circ}$ the bubble is fixed fixed. At $\alpha=20^{\circ}$ a rapid growth and separeration area behind the trailing edge is observed. This separation behavior is more evident in NACA4415 being a non symmetrical airfoil. Upon comparing various ice profiles, the trailing edge separation with the clean airfoil is clearly evident. However with the horn ice, the flow separation is observed for all angle of attack.

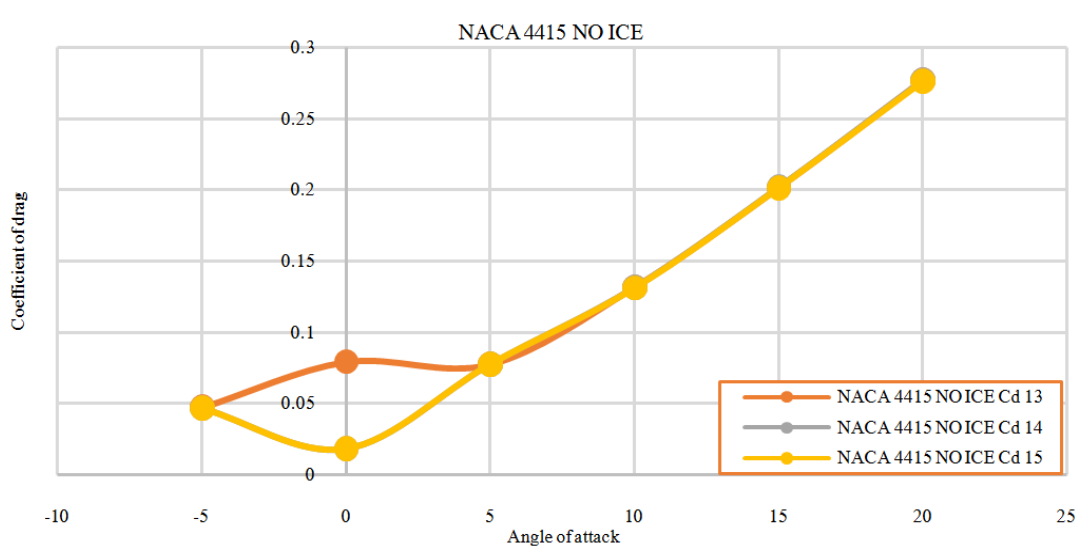

Fig. 4. $C_{D}$ NACA 4415 with no-ice

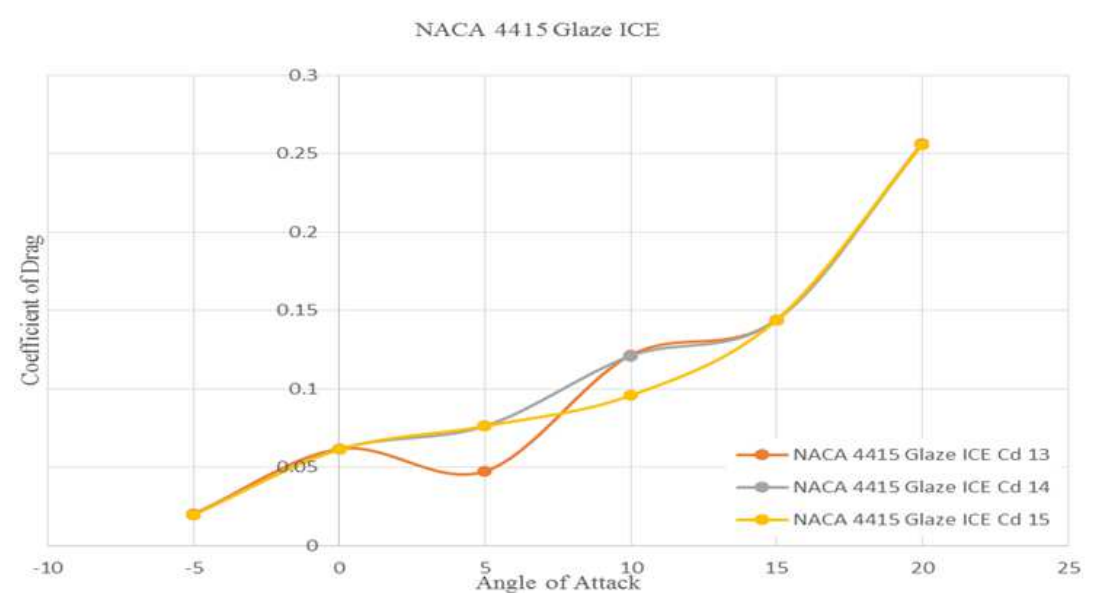

Fig. 5. $C_{D}$ : NACA 4415 with glaze ice 
NACA 4415 Horn Ice

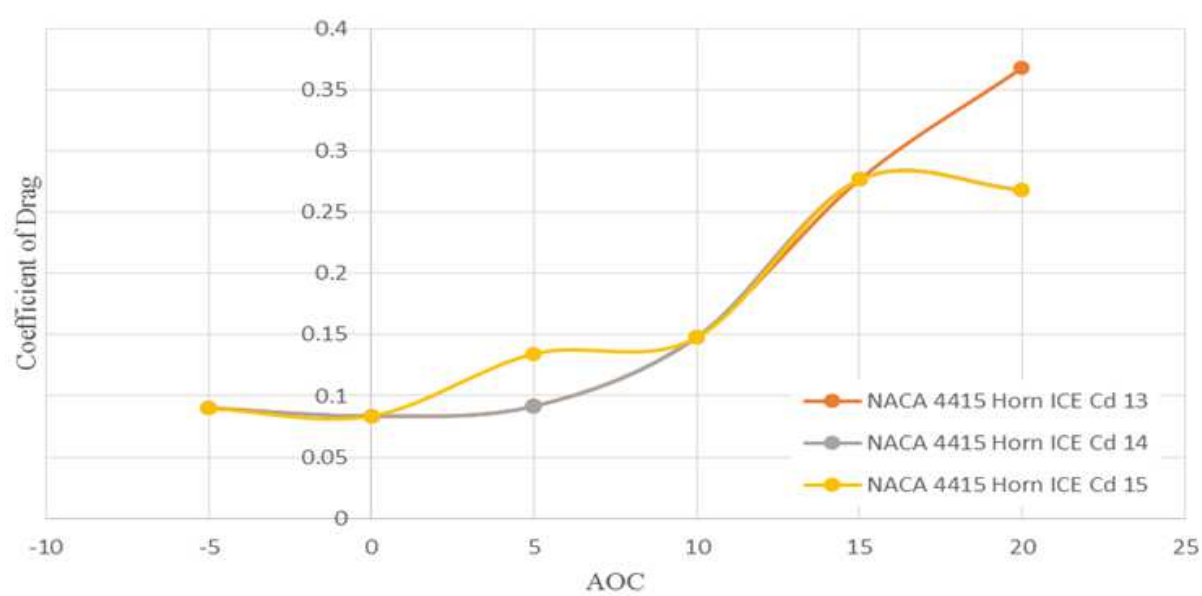

Fig. 6. $C_{D}$ : NACA 4415 with horn ice

\section{NACA 4415 NO ICE}

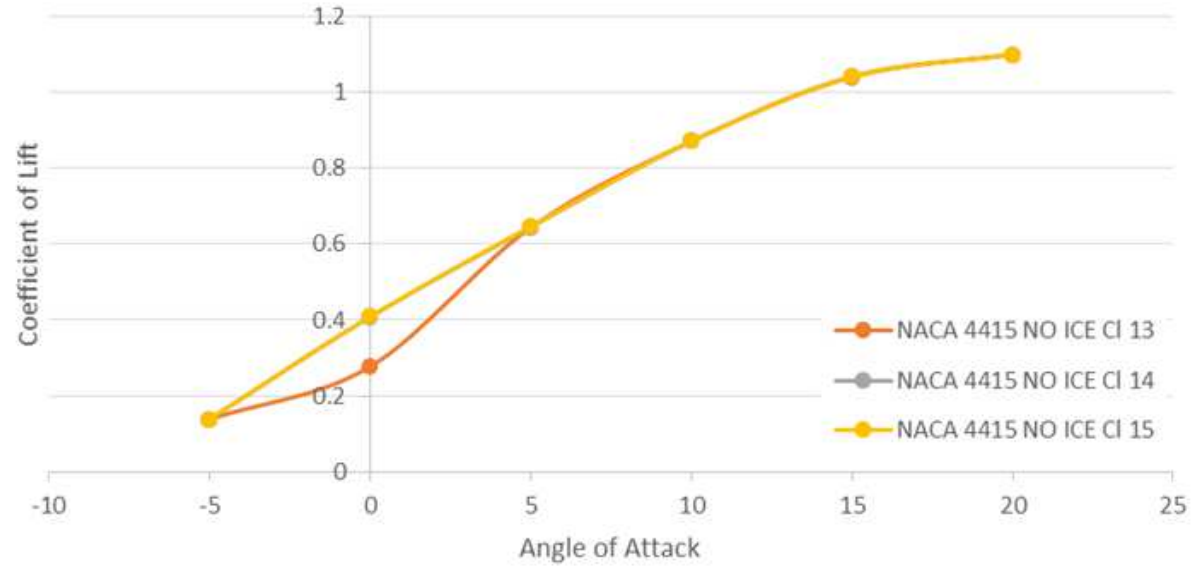

Fig. 7. $\mathrm{C}_{\mathrm{L}} \mathrm{NACA} 4415$ with no-ice

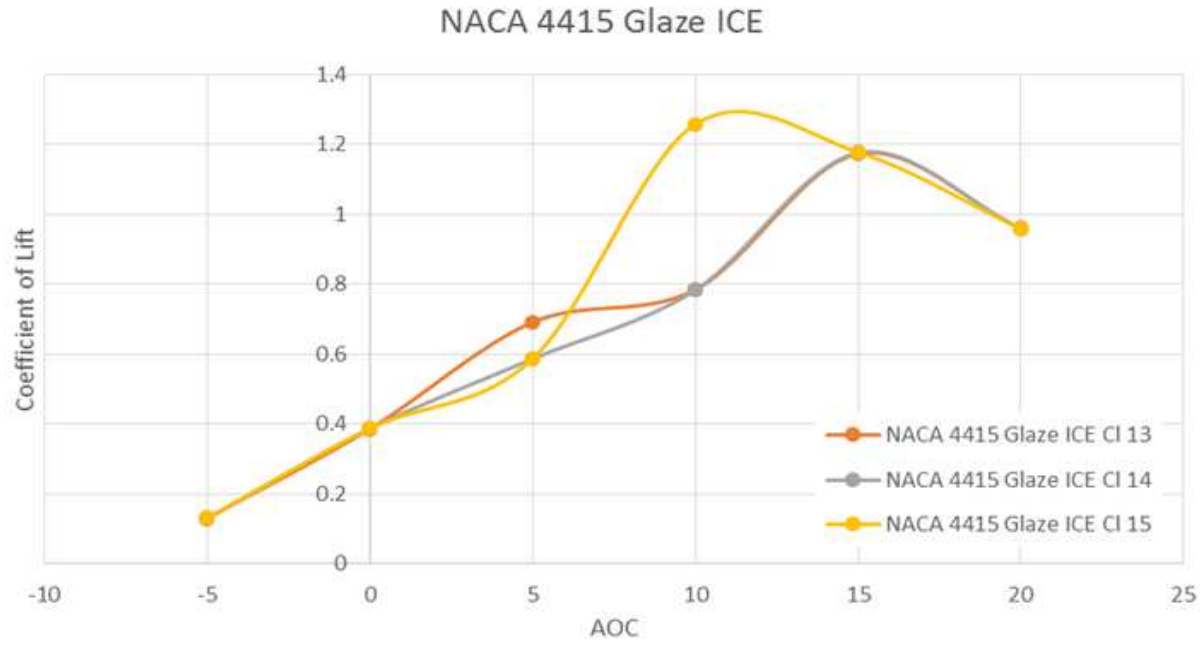

Fig. 8. $\mathrm{C}_{\mathrm{L}}$ : NACA 4415 with glaze ice 


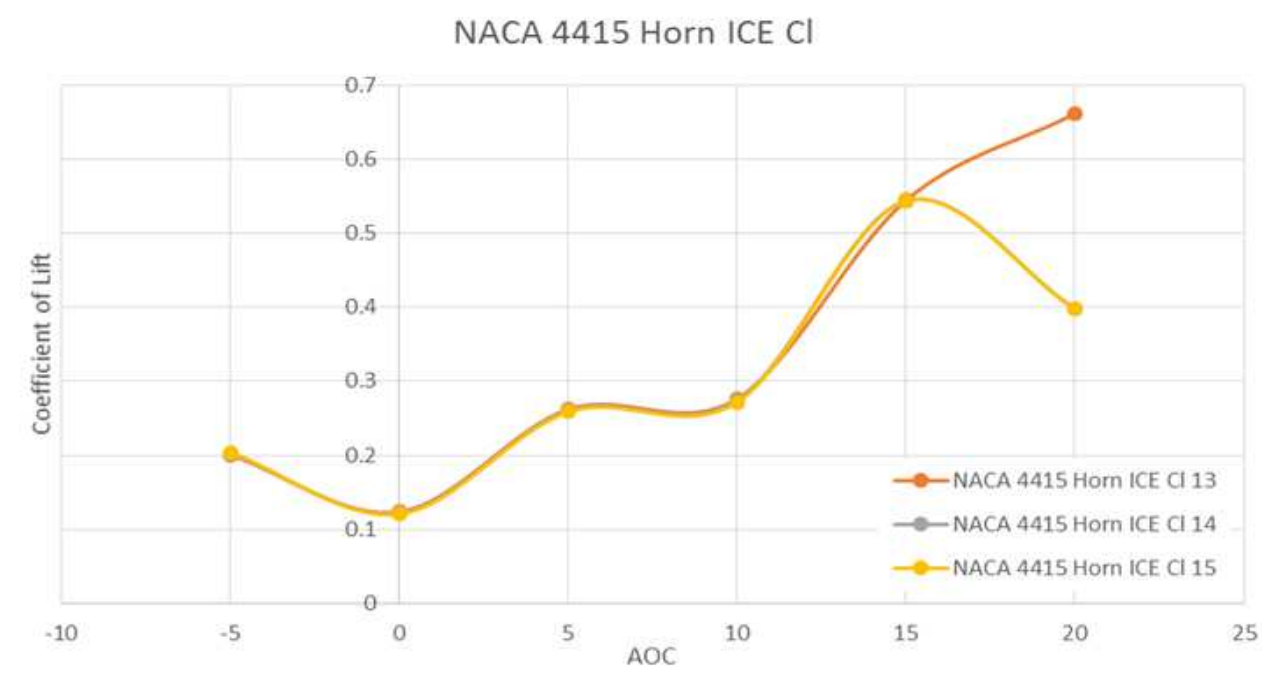

Fig. 9. $\mathrm{C}_{\mathrm{L}}$ : NACA 4415 with horn ice

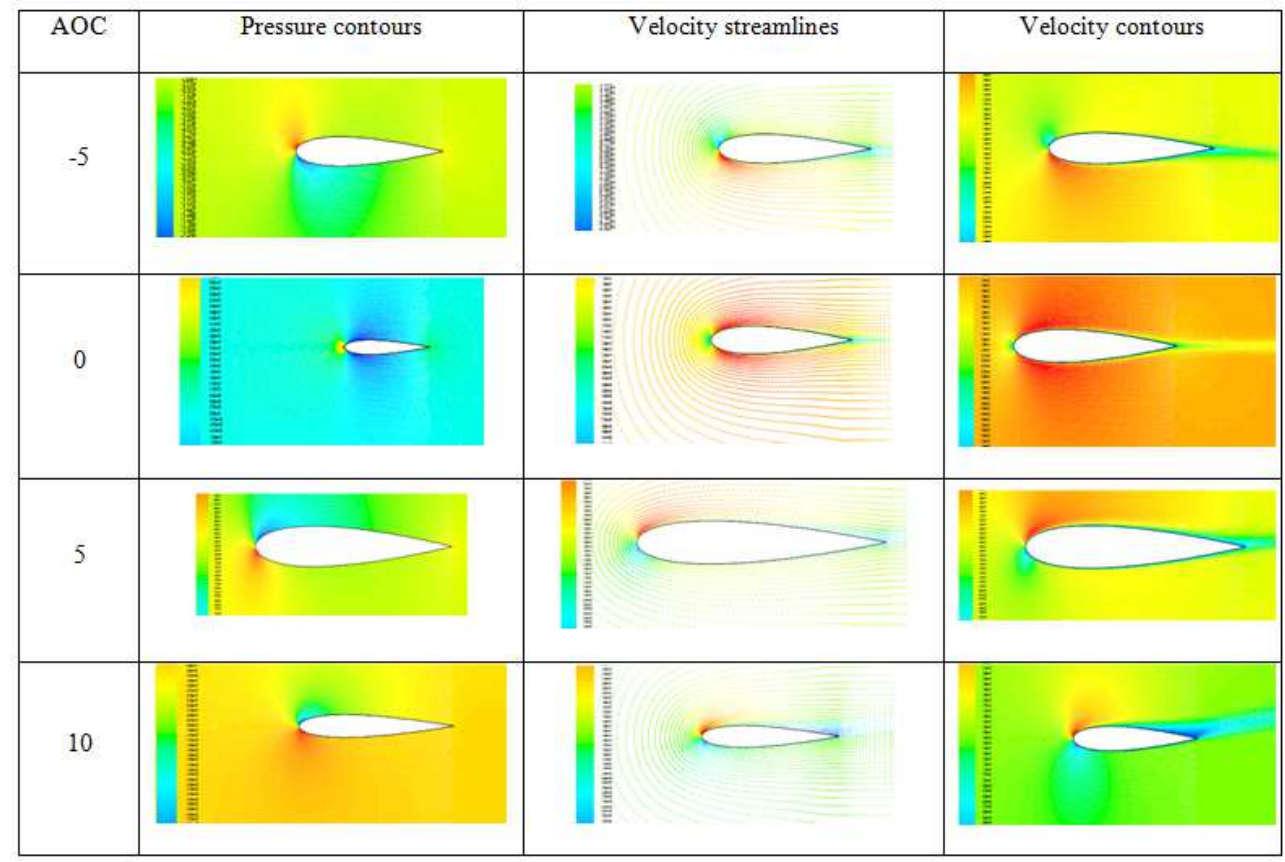

Fig. 10. Flow characteristic of NACA0012 with no ice

It is also observed that the slightest lift reduction and drag developments were caused by glaze ice accretion. It is because, the water droplets froze upon impact at the leading edge and this deposition contributed as an extention to the leading edge, hence causing less flow disturbance. However, in cases of horn ice, some of the droplets which had not frozen immediately resulted in a re-disturbed flow field. The horn ice had the maximum negative influence on the flow by premature flow separation and thereby increased lift degradation. It is also observed that the horn ice caused the most flow scatter in both
NACA0012 and NACA4415. Analyzing the horn ice simulation, its is observed that the sharp edges at the suction leads to rapid increase of flow velocity. Which are also seen in plots for velocity streamlines. Due to which, large separation bubble were seen. The velocity profiles demonstrated the pressure on the lower side is greater than the incoming flow stream and resulted in lifting the airfoil upward. Small vortices on ice peaks causing recirculation zones were also evident on the suctions side, leading to significant flow disturbance and retardation. 


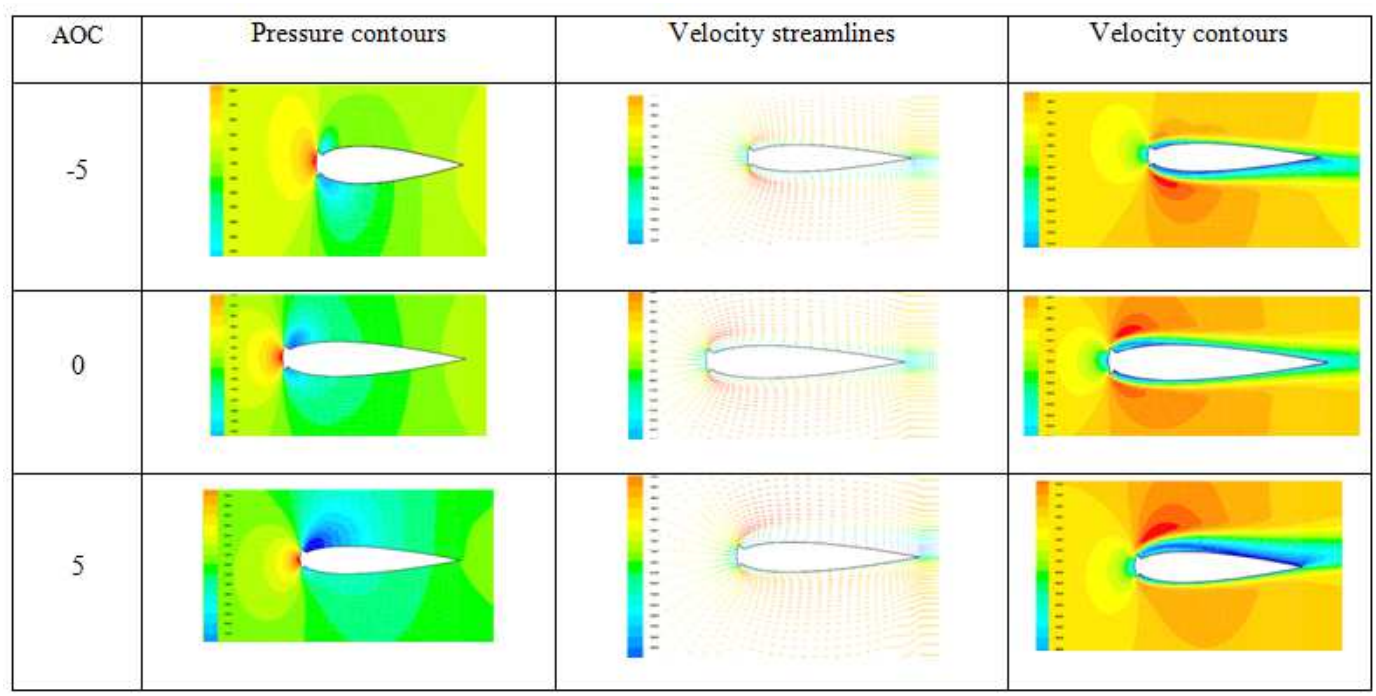

Fig. 11. Flow characteristic of NACA0012 with horn ice

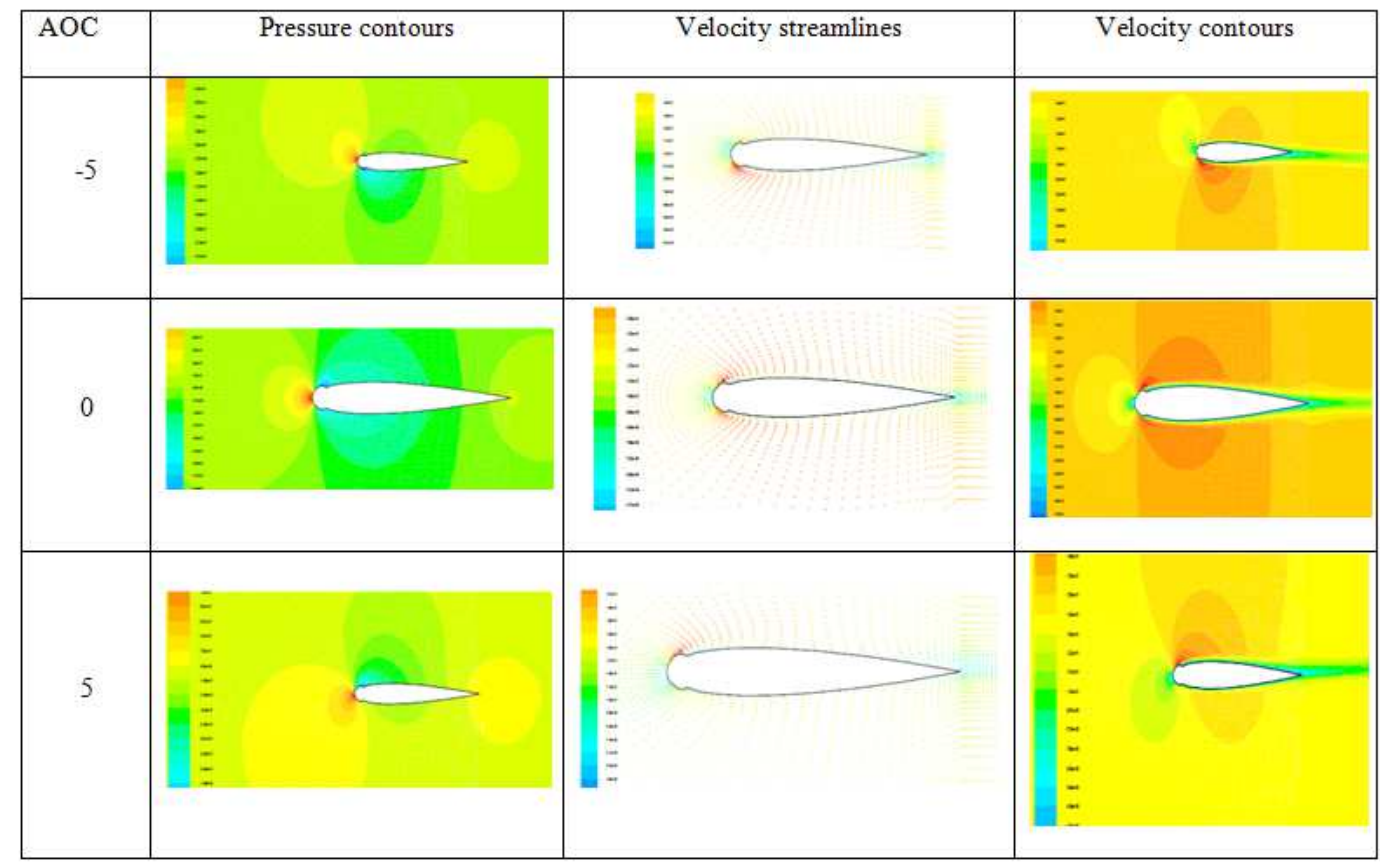

Fig. 12. Flow characteristic of NACA0012 with glaze ice

In case of glaze ice, the flow characteristics observed was similar to that of the clean airfoil. It was also observed that the magnitude of velocity did not differ significantly from the clean profile. Components for the velocity contours confirmed slight migration of the stagnation point towards the trailing edge and raplidy jump to the the leading edge at lower angle of attack. A stagnation point is experienced in a flow field when velocity of the fluid is zero. The suction side of the airfoil experienced a higher velocity compared to the pressure surface. This was also evident from the pressure distribution across the airfoil. As the AOA increased, the upper surface velocity was much higher than the velocity on the lower surface. The velocity of the upper surface is fast moving when compared to the lower surface. The flow accelerates on the upper surface as seen from the change in colors of the vectors. On the trailing edge, the flow on the upper surface decelerates and converges with the flow on the lower surface. 
The lift and drag coefficient shown for NACA0012 and NACA4415 with and without ice profile shows the dimensionless lift coefficient increased linearly with the increasing angle of attack. Flow was attached to the airfoil throughout this phase for $\mathrm{AOA}-5^{\circ}$ to $10^{\circ}$. At an $15^{\circ}$, the flow on the upper surface of the airfoil began to separate into a state known as stall. The clean, glaze ice and horn ice, had a good agreement and the same behavior was observed at all AOA until stall.

Turbine power losses were observed in coefficient of drag and lift for NACA0012 and NACA4415. It is evident that larger ice profiles at higher AOA contributed significantly to greater power losses as the coefficient of drag increased. However, the coefficient of lift decreased at higher AOA until a complete stall was observed. Fig. 4-9 has exemplified the coefficients of drag and lift for NACA 4415 airfoil with no ice, glaze ice and horn ice with respect to the AOA.

From Equation 2, increase in drag is directly proportional to increased coefficient of performance. The ratio for coefficient of drag and lift for $\mathrm{C}_{\mathrm{D}} / \mathrm{C}_{\mathrm{L}}$ was directly proportional to the coefficient of performance. From Equation 1, the turbine power output is a product of wind power and coefficient of performance. Thus it can be proven that as coefficient of drag increases with the increasing ice profiles, the coefficient of performance also increases. Based on this relationships, we can conclude that the icing significantly increases drag on the wind turbine and in turn contributes significantly in reducing power generation.

Fom Table 2, it is seen that coefficient of performance increases along with the ratios $C_{D} \backslash C_{L}$.

At higher velocities, It is also observed that there is a significant increase in the ratio for horn ice when compared to glaze ice or clean ice with the increasing AOA. The glaze and clean ice profiles are closely related due to minimal airfoil deformation therefore resulting in no flow separation. In some cases, glaze ice is efficient than clean ice without contributing to flow separation.

From the modified Betz equation and Table 2, as the AOA increased, we find that the increase $C_{D} \backslash C_{L}$ ratios for the horn ice profiles decreased its aerodynamic efficiency. With the higher values for coefficient of performance resulting from the higher drag ratio, the power output from turbine is seen to significantly reduce. However the differences between glaze ice and clean ice profiles were very analogous.

Stall characterisitcs of an airfoil is a result from a substantial flow separation. Stall is a phenomenon where the airfoil fails to perform as a result of decresed lift and increased drag over the airfoil surface. Flow separation is seen on ice profiles for NACA 0012 and NACA 4415 at AOA $10^{\circ}$ or larger. A clean airfoil also experiences stall when the critical angle exceeded $15^{\circ}$. Similarly stall can also be triggered if the surface of the wind turbine rotor blade is uneven.

Table 2. Comparison of $\mathrm{C}_{\mathrm{D}} / \mathrm{C}_{\mathrm{L}}$ ratios to evaluate coefficient of performance

\begin{tabular}{|c|c|c|c|c|c|c|c|}
\hline \multirow[b]{2}{*}{ Velocity (m\s) } & \multirow[b]{2}{*}{ Angle of attack $\left(^{\circ}\right)$} & \multicolumn{3}{|c|}{ NACA0012 } & \multicolumn{3}{|c|}{ NACA4415 (Parent S807) } \\
\hline & & No ice & Glaze ice & Horn ice & No ice & Glaze ice & Horn ice \\
\hline \multirow{7}{*}{13} & & $\mathrm{C}_{\mathrm{D}} \backslash \mathrm{C}_{\mathrm{L}}$ & $\mathrm{C}_{\mathrm{D}} \backslash \mathrm{C}_{\mathrm{L}}$ & $\mathrm{C}_{\mathrm{D}} \backslash \mathrm{C}_{\mathrm{L}}$ & $\mathrm{C}_{\mathrm{D}} \backslash \mathrm{C}_{\mathrm{L}}$ & $\mathrm{C}_{\mathrm{D}} \backslash \mathrm{C}_{\mathrm{L}}$ & $\mathrm{C}_{\mathrm{D}} \backslash \mathrm{C}_{\mathrm{L}}$ \\
\hline & -5 & 0.045 & 0.134 & 0.336 & 0.340 & 0.155 & 0.451 \\
\hline & 0 & 0.723 & 0.379 & 0.818 & 0.286 & 0.160 & 0.678 \\
\hline & 5 & 0.045 & 0.126 & 0.376 & 0.121 & 0.169 & 0.350 \\
\hline & 10 & 0.555 & 0.188 & 0.486 & 0.152 & 0.155 & 0.537 \\
\hline & 15 & 0.212 & 0.294 & 0.495 & 0.194 & 0.123 & 0.508 \\
\hline & 20 & 0.314 & 0.384 & 0.554 & 0.252 & 0.267 & 0.556 \\
\hline \multirow{7}{*}{14} & & $\mathrm{C}_{\mathrm{D}} \backslash \mathrm{C}_{\mathrm{L}}$ & $\mathrm{C}_{\mathrm{D}} \backslash \mathrm{C}_{\mathrm{L}}$ & $\mathrm{C}_{\mathrm{D}} \backslash \mathrm{C}_{\mathrm{L}}$ & $\mathrm{C}_{\mathrm{D}} \backslash \mathrm{C}_{\mathrm{L}}$ & $\mathrm{C}_{\mathrm{D}} \backslash \mathrm{C}_{\mathrm{L}}$ & $\mathrm{C}_{\mathrm{D}} \backslash \mathrm{C}_{\mathrm{L}}$ \\
\hline & -5 & 0.045 & 0.141 & 0.335 & 0.339 & 0.151 & 0.446 \\
\hline & 0 & 0.407 & 0.501 & 0.822 & 0.045 & 0.159 & 0.686 \\
\hline & 5 & 0.044 & 0.134 & 0.377 & 0.120 & 0.130 & 0.352 \\
\hline & 10 & 0.055 & 0.188 & 0.486 & 0.151 & 0.155 & 0.540 \\
\hline & 15 & 0.212 & 0.294 & 0.495 & 0.194 & 0.122 & 0.509 \\
\hline & 20 & 0.313 & 0.384 & 0.554 & 0.252 & 0.267 & 0.674 \\
\hline \multirow{7}{*}{15} & & $\mathrm{C}_{\mathrm{D}} \backslash \mathrm{C}_{\mathrm{L}}$ & $\mathrm{C}_{\mathrm{D}} \backslash \mathrm{C}_{\mathrm{L}}$ & $\mathrm{C}_{\mathrm{D}} \backslash \mathrm{C}_{\mathrm{L}}$ & $\mathrm{C}_{\mathrm{D}} \backslash \mathrm{C}_{\mathrm{L}}$ & $\mathrm{C}_{\mathrm{D}} \backslash \mathrm{C}_{\mathrm{L}}$ & $\mathrm{C}_{\mathrm{D}} \backslash \mathrm{C}_{\mathrm{L}}$ \\
\hline & -5 & 0.044 & 0.134 & 0.355 & 0.377 & 0.149 & 0.441 \\
\hline & 0 & 0.268 & 0.204 & 0.813 & 0.044 & 0.158 & 0.694 \\
\hline & 5 & 0.044 & 0.134 & 0.379 & 0.120 & 0.130 & 0.520 \\
\hline & 10 & 0.055 & 0.187 & 0.487 & 0.151 & 0.076 & 0.544 \\
\hline & 15 & 0.212 & 0.294 & 0.495 & 0.194 & 0.122 & 0.509 \\
\hline & 20 & 0.313 & 0.384 & 0.554 & 0.252 & 0.267 & 0.674 \\
\hline
\end{tabular}




\section{Conclusion}

A computational study was performed to evaluate airfoil performance with ice accretions. Flow models were evaluated for various angles of attack on clean and iced airfoils (NACA0012 and NACA4415). Results confirm that the aerodynamic performance of airfoil is more sensitive to the horn ice accretion at the leadingedge when compared with no ice and glazed ice profiles. Similarly $C_{D} / C_{L}$ ratios were significantly higher in horn ice in comparison to other sampled profiles. There were no noteworthy differences between ice shapes and velocities examined. Also results between no-ice and glazed iced profiles had marginal differences. From the flow patterns observed in this study, it is learnt that the ice accumulation modified the pressure distribution and influenced flow patterns and the overall airfoil performance. Simulation results also confirmed elevated ice accretion significantly reduced airfoil performance. For various ice shape, modified Betz equations established relationship between coefficients of performance and wind turbine efficiency.

\section{Acknowledgment}

The authors would like to acknowledge Washington State Univerity, School of Mechanical and Material Engineering for providing extensive guidance in developing the ice model.

\section{Funding Information}

This effort was supported by Washington State Univeristy and partly funded by Bechtel National.

\section{Author's Contributions}

All authors had equal contribution at all stages including discussions, methods and results.

Aditya Bagade: Modeled and analyzed icing models using ANSYS 14.

Changki Mo: Reviewed, provided guidance and feeback on experiemntal approach and data analysis.

Abdelhamid Mazher: Provided oversight and assisted with model development.

\section{Ethics}

This article contains original content while preserving highest integrity in performing analysis and presenting results.

\section{References}

Ahmed, M.A., F. Ahmed and M.W. Akhtar, 2010. Wind characteristics and wind power potential for southern coasts of Sindh, Pakistan. J. Basic Applied Sci., 6: 163-163.
Ahmed, T., T. Amin, R. Islam and S. Ahmed, 2013. Computational study of flow around a NACA 0012 wing flapped at different flap angles with varying mach numbers. Global J. Res. Eng.

Cao, Y., 2008. Flowfield simulation and aerodynamic performance analysis of complex iced aerofoils with hybrid multi-block grid. DOI: $10.1243 / 09544100$ JAERO286

Cao, Y., Q. Zhang and J. Sheridan, 2008. Numerical simulation of ice accretion on airfoils. Proceedings of the ICTAM, Aug. 25-29, Adelaide, Australia, pp: 1-2.

Chantharasenawong, C. and W. Tipkaew, 2010. Determination of wind turbine blade flapwise bending dynamics. Proceedings of the TSME International Conference on Mechanical Engineering. Oct. 20-22, Ubon Ratchathani, pp: 1-6.

Corbus, D. and M. Meadors, 2005. Small wind research turbine final report. Technical Report NREL/TP500-38550.

DIANE, 2005. National Renewable Energy Laboratory Institutional Plan: 2001-2005. DIANE Publishing.

Ganander, H. and G. Ronsten, 1998. Design load aspects due to ice loading on wind turbine blades. Proceedings of the BOREAS VI Conference. Finnish Meteorological Institute, 2003.

Gregory, N. and C.L. O'Reilly, 1970. Coefficient of pressure along the airfoil for the experimental data. NASA R\&M.

Hudecz, A., H. Koss and M. Hansen, 2013. Ice accretion on wind turbine blades. Proceedings of the IWAIS, Newfoundland and Labrador, Sept. 811, St. Johns Canada.

Ingram, G., 2011. Wind turbine blade analysis using the blade element momentum method. Version 1.1.

Jasinski, W.J., S.C. Noe, M.S. Selig and M.B. Bragg, 1998. Wind turbine performance under icing conditions. Trans. ASME, J. Solar Energy Eng., 120: 60-65.

JAVA, 2007. JavaFoil-Analysis of Airfoils. JAVA.

Johnson, G.L., 1985. Wind Energy Systems. 1st Edn., Prentice Hall PTR, Englewood Cliffs, ISBN-10: 0139577548, pp: 360.

Lee, S. and M.B. Bragg, 2003. Investigation of factors affecting iced-airfoil aerodynamics. J. Aircraft, 40: 499-508.

Liu, C. and Y. Wang, 2011. Numerical analysis of ice accretion effects at super-cooled large droplet conditions on airfoil aerodynamics. J. Modern Trans., 19: 274-278. DOI: 10.1007/BF03325769

Parent, O. and A. Ilinca, 2011. Anti-icing and de-icing techniques for wind turbines: Critical review. Cold Regions Sci. Technol., 65: 88-96. DOI: $10.1016 /$ j.coldregions.2010.01.005

Salim, M. and S.C. Cheah, 2009. Wall $\mathrm{y}^{+}$strategy for dealing with wall-bounded turbulent flows. Proceedings of International Multi Conference of Engineers and Computer Scientists, Mar. 18-20, Hong Kong, pp: 1-6. 
Shields, D., 2011. A Modeling study of ice accretion on a NACA 4412 airfoil. Rensselaer Polytechnic Institute.

Sicot, C., P. Devinant, S. Loyer and J. Hureau, 2008. Rotational and turbulence effects on a wind turbine blade. Investigation of the stall mechanisms. J. Wind Eng. Industrial Aerodyn., 96: 8-9.

DOI: 10.1016/j.jweia.2008.01.013

Tsao, J. and S. Lee, 2011. Evaluation of icing scaling on swept NACA 0012 airfoil models. SAE Technical Paper. DOI: $10.4271 / 2011-38-0081$

UIUC, 2011. Airfoil Coordinates Database. UIUC.

Villalpando, F., M. Reggio and A. Ilinca, 2012. Numerical study of flow around iced wind turbine airfoil. Eng. Applications Computational Fluid Mechanics, 6: 39-45.

WTPC, 1999. Wind turbine power curves.

Zhou, H. And S.L. Hu, 2006. Numerical analysis of the aerodynamic performance of an airfoil with round Ice. Chinese Quarterly Mechanics, 28: 28-33.

\section{Nomenclature}

A Cross sectional area of Flow.

V Velocity of the Fluid flowing over the Airfoil

A Angle of Attack

$\mathrm{C}_{\mathrm{L}} \quad$ Coefficient of lift

$\mathrm{C}_{\mathrm{D}} \quad$ Coefficient of drag

$\mathrm{C}_{\mathrm{P}} \quad$ Pressure Coefficient

$\mathrm{Cp}_{\mathrm{i}} \quad$ Coefficient of performance

$\Lambda \quad$ Tip speed ratio

$\lambda_{\mathrm{r}} \quad$ Local tip speed

$\beta \quad$ Relative flow angle into blades

Q Tip loss correction factor

a' Angular induction factor

a Axial induction factor

$\mathrm{Sm} \quad$ Mass added to the continuous phase from the dispersed second phase

$\tau \quad$ Stress tensor

$\Omega \quad$ Blade rotational speed

$\rho \quad$ Density of stream air

$\mathrm{R} \quad$ Blade tip radius

F Model dependent sources

V Absolute velocity 